\title{
Natural history of amblyopia untreated owing to lack of compliance
}

Kurt Simons, Mark Preslan

\begin{abstract}
Aims-A prospective study of the efficacy of amblyopia treatment in preschool children has recently been called for, requiring an untreated control group. The present study assessed data from patients with amblyopia untreated owing to lack of compliance, or with amblyopia risk factors, to determine outcome.

Methods-Longitudinal data were obtained from 18 4-6 year old patients who had initially been screened for amblyopia, strabismus, and/or bilateral refractive error, failed to comply with prescribed treatment, and in whom amblyopia was detected at a rescreening approximately a year later. The data from three previous studies comparing outcome of patients compliant and non-compliant with amblyopia treatment were also reanalysed.
\end{abstract}

Results-One child of the 18 , who wore glasses sporadically, showed some improvement in visual acuity in the amblyopic eye. Otherwise, no child showed an improvement, and seven of the 17 (41\%) for whom visual acuities were available at both screenings showed a deterioration of visual acuity in the amblyopic eye, including three who apparently developed amblyopia for the first time. A child with an ametropic risk factor for amblyopia whose visual acuity was not obtained at the first screening and who was largely noncompliant presented with amblyopia at the second screening. The reanalysed data from the three previous studies demonstrated a significantly poorer visual acuity outcome in the amblyopic eye in the noncompliant patient groups than in the compliant groups in each study.

Conclusion-Preschool children with amblyopia or its risk factors are at risk of having the current amblyopia deteriorate, or of developing amblyopia, if not treated. These results raise questions about the ethical acceptability of a prospective study of amblyopia treatment at these ages.

(Br F Ophthalmol 1999;83:582-587)

Department of Ophthalmology, University of

Maryland, Baltimore, USA

M Preslan

Correspondence to: Kurt Simons, Krieger Children's Eye Center, The Wilmer Eye Institute, Johns Hopkins Hospital, Baltimore, MD 21287-9028, USA.

Accepted for publication 12 November 1998 pertral and a for the detection, is the lack of an adequate prospective study based demonstration of the efficacy of amblyopia treatment. ${ }^{129}$ It calls for such study to be made. ${ }^{129}$ A prospective study requires that the control cases involved should not be treated, the ethics of which in this context are controversial. ${ }^{5}{ }^{10}$ The report contends that such study is feasible in this respect because research findings "do not support the need to treat" amblyopic children (p 20, p $16^{2}$ ). Indeed, it concludes, on the basis of six cited studies, ${ }^{11-16}$ that "mild degrees of amblyopia may resolve spontaneously" (p 2, $\mathrm{p}$ iii $^{2}$. However, there are many variables that need to be taken into account in interpretation of such data. ${ }^{17}$ We here report longitudinal data on the course of amblyopia in a group of children detected in a screening study who were not prescribed or did not comply with recommended treatment, and then were retested a year later in a follow up screening. Reanalysis of similar data from previous studies was also made.

\section{Methods}

PART I

As part of a demonstration screening project, one of the authors (MP) screened the ocular status of a group of preschool and school age children at an inner city elementary school, ${ }^{18}$ and then returned 1 year later and rescreened the same group. ${ }^{19}$ Visual acuity was determined in both cases with an isolated Snellen E at a 10 foot testing distance, and cover testing conducted with the child fixating a near target. Any child achieving poorer visual acuity than $10 / 15$ (20/30 equivalent) in either eye, or with a manifest deviation, was given a standard eye examination by one of the authors (MP), including alternate cover testing with fixation on a near target, cycloplegic retinoscopy using cyclopentolate $1 \%$ and tropicamide $1 \%$ ophthalmic drops, and indirect ophthalmoscopy. The examiner was masked to the results of the visual acuity and cover testing. All children failing the clinical examination were offered treatment, ${ }^{18}$ and efforts were made to monitor and encourage compliance. ${ }^{19}$ Fifteen children exhibiting amblyopia at the first screening remained in the school population and were thus retested at the second screening. Forty two children failing the initial screening bilaterally but exhibiting equal vision in both eyes in that screening were also retested. All 18 of the children found amblyopic at the second screening, ranging in age at the first screening from 4 to 6 years, either had received glasses but no further treatment or had not been taken for treatment at the time of the second examination. Their results thus provided longitudinal data on the course of untreated amblyopia. 
Table 1 Patient data

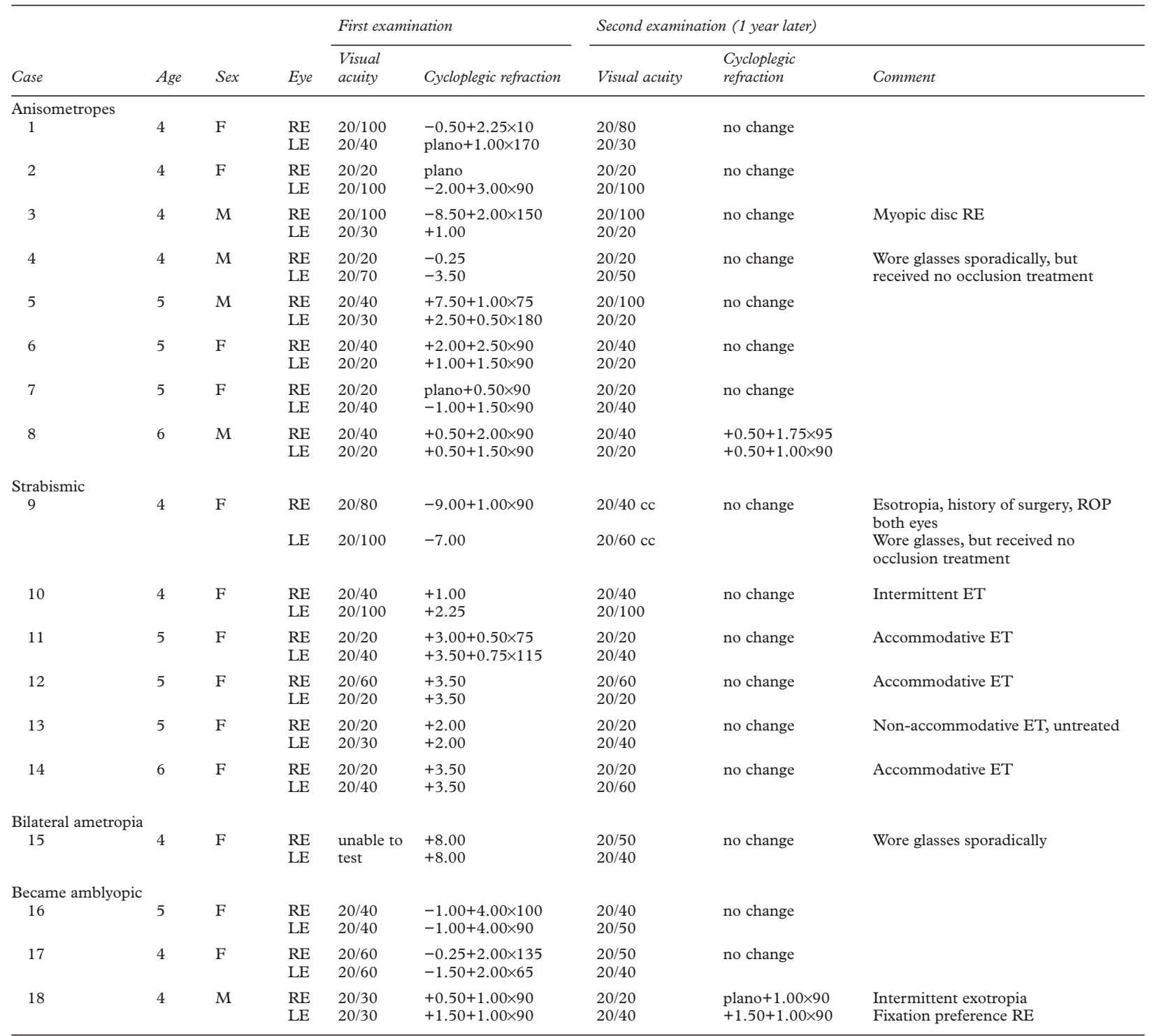

$\mathrm{cc}=$ with correction.

PART II

Data from three previous studies ${ }^{20-22}$ which reported amblyopia treatment outcome results of both compliant and non-compliant patients were reanalysed statistically.

\section{Results}

PART I

One child, an anisometropic amblyope who wore glasses only sporadically, indicated a slight improvement in the (corrected) amblyopic eye's acuity (Table 1, case 4) and another anisometropic amblyope indicated some acuity improvement in both eyes, with a slight reduction in difference in acuity between eyes that appears to have been an artefact of the acuity test intervals (case 1). Otherwise, of the 15 amblyopic children for whom (uncorrected) acuity measurements were available at both visits, none showed spontaneous improvement, eight showed no change in their amblyopia (cases 2, 6-12), one who wore glasses sporadically showed bilateral improvement but no reduction in acuity difference between eyes (case 8), and four showed deterioration in the form of increase of amblyopic difference in acuity between eyes (cases 3, 5, 13, 14). Three subjects who had not been found to be amblyopic at the initial screening were found to be amblyopic at the second screening (cases 16-18). A subject whose acuity could not be measured at the first visit but whose high refractive error indicated a significant risk factor was prescribed glasses (case 15). These were only worn sporadically, however, and amblyopia was diagnosed in this latter case at the second screening.

PART II

In the first set of study data reanalysed here, the compliance index was whether cessation of treatment occurred as the result of following instructions by an orthoptist-indicating that cessation represented completion of treatment-or whether cessation was due to failure to comply with this requirement, or simply to come for appointments at all. ${ }^{20}$ Our 
Table 2 Patient data from Hiscox et al ${ }^{20}$

\begin{tabular}{|c|c|c|c|c|c|c|}
\hline \multirow{2}{*}{$\begin{array}{l}\text { Reason treatment } \\
\text { stopped }\end{array}$} & \multicolumn{5}{|c|}{ Outcome visual acuity } & \multirow[b]{2}{*}{ Total } \\
\hline & $6 / 9$ & \multicolumn{2}{|c|}{$6 / 12-6 / 18$} & $<6 / 18$ & Missing cases & \\
\hline Orthoptist instructions & $125(42 \%)$ & \multicolumn{2}{|c|}{$96(32 \%)$} & $59(20 \%)$ & $16(5 \%)$ & $296(100 \%)$ \\
\hline $\begin{array}{l}\text { Non-compliance, } \\
\text { failure to attend }\end{array}$ & $10(18 \%)$ & \multicolumn{2}{|c|}{$18(32 \%)$} & $21(37 \%)$ & $8(14 \%)$ & $57(100 \%)$ \\
\hline \multicolumn{7}{|c|}{$\begin{array}{l}\chi^{2} \text { for trend without missing cases: } \mathrm{p}<0.0002 \\
\chi^{2} \text { with missing cases: } \mathrm{p}<0.0002\end{array}$} \\
\hline \multicolumn{7}{|c|}{ Table 3 Patient data adapted from Williamson et al $2^{2}$} \\
\hline Compliance & \multicolumn{2}{|c|}{$\begin{array}{l}\text { Amblyopic eye } \\
\text { acuity deteriorated } \\
(\%)\end{array}$} & \multicolumn{2}{|c|}{$\begin{array}{l}\text { Amblyopic eye } \\
\text { acuity stable } \\
(\%)\end{array}$} & $\begin{array}{l}\text { Amblyopic eye } \\
\text { acuity improved } \\
(\%)\end{array}$ & Total \\
\hline Completed treatment & $25(6 \%)$ & & 133 & $32 \%)$ & $257(61 \%)$ & $415(100 \%)$ \\
\hline Defaulted on treatment & $25(11 \%)$ & & 122 & $54 \%)$ & $78(35 \%)$ & $225(100 \%)$ \\
\hline
\end{tabular}

\begin{tabular}{lcccc}
\hline \multirow{5}{*}{ Group } & \multicolumn{2}{l}{ Outcome visual acuity } & & \\
\cline { 2 - 5 } & $20 / 30$ or better & $20 / 40-20 / 60$ & $20 / 70$ or worse & Total \\
\hline Medicaid & $19(26.8 \%)$ & $28(39.4 \%)$ & $24(33.8 \%)$ & $71(100 \%)$ \\
Non-Medicaid & $122(58.4 \%)$ & $63(30.1 \%)$ & $24(11.5 \%)$ & $209(100 \%)$ \\
\hline
\end{tabular}

$\chi^{2}$ for trend: $\mathrm{p}<0.0001$.

reanalysis demonstrates that patients not complying with treatment as measured by this index were significantly more likely to have poorer visual acuity outcome, whether or not missing cases are included in the calculation (Table 2). Reanalysis of the results of a second study also found that patients who defaulted on completion of treatment had a significantly greater likelihood of falling lower on a spectrum stretching from "deteriorated" to "stable" to "improved" than those completing their treatment programme (Table 3). ${ }^{21}$ (Analysis in the original study found treatment default level to be statistically significantly related to the attendance rate used as the compliance measure..$^{21}$ ) In a third study, reanalysis showed once again that non-compliant patients (Medicaid group) exhibited a significantly worse visual acuity outcome than compliant patients (non-Medicaid group) ${ }^{22}$ (Table 4 ).

In summary, these studies indicate that the visual outcome of children whose amblyopia is treated is significantly better than the outcome of children in which there is reduced or no treatment.

\section{Discussion}

It should be noted at the outset that studies involving non-random samples of screened or clinical populations do not fully fit the definition of the term "natural history". ${ }^{23}$ We here use the more limited characterisation of "natural history of untreated amblyopia". Most of the handful of previous reports, then, have comprised cases of untreated infantile esotropia who presented as adults. ${ }^{16}{ }^{24}$ However, there is some question of the pertinence of these findings to small angle strabismic patients since, as these studies point out, ${ }^{1624}$ the large angle deviation associated with infantile esotropia appears more likely to give rise to alternation than amblyopia, as demonstrated by the onset of apparently iatrogenic amblyopia that often follows surgical reduction in size of these patients' misalignments. ${ }^{16}$ Another study collected a group of untreated cases, primarily of strabismic amblyopia, who presented as older children and compared the acuity of the amblyopic eye with that of a group of patients presenting as adults. ${ }^{25}$ This study found the mean acuity of the adult group to be significantly lower than that of the child group, and concluded that there was further acuity deterioration in the (untreated) amblyopic eye during adolescence. ${ }^{25}$ However, this study was cross sectional and used patients drawn from clinical practices whose selection may have been subject to biases of both presentation and selection.

Longitudinal data are preferable to cross sectional data for demonstrating natural history effects since variables other than the amblyopia are controlled for. The only longitudinal data reported in which treatment was intentionally withheld would appear to be the four patients of the study by Hård et $a l^{12}$ discussed below (Table 5). The present study, and the other studies reanalysed here,${ }^{20-22}$ provide untreated history data derived from patient non-compliance with prescribed amblyopia treatment.

With the exception of one child, who wore glasses sporadically, no child in our case series showed improvement in the level of amblyopia (Table 1). Seven of 17 (41\%) for whom acuity measurements were available at both visits deteriorated, including three who apparently developed amblyopia between the two examinations (Table 1) (although case 17's amblyopia may have been masked at the first examination by the low level of bilateral visual acuity).

A previous study reported a significant association between amblyopia treatment compliance, as measured by percentage of prescribed appointments kept during the first year

Table 5 Patient data from Hård et al ${ }^{12}$

\begin{tabular}{|c|c|c|c|c|c|c|c|}
\hline Case & Eye & $\begin{array}{l}\text { Visual acuity } \\
\text { at } 4 \text { years }\end{array}$ & $\begin{array}{l}\text { Cycloplegic refraction } \\
\text { at } 4 \text { years }\end{array}$ & $\begin{array}{l}\text { Visual acuity } \\
\text { at } 5 \text { years }\end{array}$ & $\begin{array}{l}\text { Cycloplegic refraction } \\
\text { at } 5 \text { years }\end{array}$ & $\begin{array}{l}\text { Treatment at } \\
5 \text { years }\end{array}$ & $\begin{array}{l}\text { Final visual } \\
\text { acuity }^{*}\end{array}$ \\
\hline \multirow[t]{2}{*}{1} & $\mathrm{RE}$ & 0.65 & +4.50 & 0.8 & +4.00 & \multirow[t]{2}{*}{ glasses } & $0.9 \mathrm{cc}$ \\
\hline & LE & 0.65 & $+4.75-0.75 \times 90$ & 0.65 & $+4.50-0.50 \times 90$ & & $0.8 \mathrm{cc}$ \\
\hline \multirow[t]{2}{*}{2} & RE & 0.65 & +3.50 & 0.65 & $+4.50-0.50 \times 0$ & \multirow[t]{2}{*}{ glasses } & $0.9 \mathrm{cc}$ \\
\hline & LE & 0.65 & $+3.25-0.50 \times 145$ & 0.65 & $+3.75-0.25 \times 0$ & & $0.9 \mathrm{cc}$ \\
\hline \multirow[t]{2}{*}{3} & $\mathrm{RE}$ & 0.8 & $+2.25-0.50 \times 0$ & $0.7^{\star}$ & +2.50 & \multirow[t]{2}{*}{ patch LE } & $0.9 \mathrm{sc}$ \\
\hline & $\mathrm{LE}$ & 0.65 & +2.00 & $0.9^{\star}$ & $+2.00-0.50 \times 90$ & & $0.9 \mathrm{sc}$ \\
\hline \multirow[t]{2}{*}{4} & RE & 0.65 & +1.50 & 0.8 & $+2.00-0.50 \times 100$ & \multirow[t]{2}{*}{ patch RE } & $1.0 \mathrm{sc}$ \\
\hline & LE & 0.65 & $+1.50-0.75 \times 90$ & 0.65 & $+2.25-1.0 \times 90$ & & $0.9 \mathrm{sc}, 1.0 \mathrm{cc}$ \\
\hline
\end{tabular}

$\star$ Tested with linear $\mathrm{E} ; \mathrm{cc}=$ with correction, $\mathrm{sc}=$ without correction. 
of treatment, and final visual acuity. ${ }^{26}$ Another study comparing a group of patients on Medicaid with a second group not on Medicaid found that the Medicaid group had a significantly worse visual acuity outcome, significantly more missed visits, and a significantly lower parent estimate based index of compliance. ${ }^{22}$ A reanalysis of this latter study's data (using a different statistical measure than that used in the original study ${ }^{22}$ ), as well as of equivalent data from two other studies, ${ }^{20}{ }^{21}$ also demonstrated that compliant patients had a significantly better visual acuity outcome than non-compliant patients (Tables 2-4). Of particular interest in one of these studies ${ }^{21}$ was the finding that approximately twice the percentage $(61 \%$ v $35 \%)$ of compliant as noncompliant eyes showed acuity improvement and, conversely, twice the percentage $(11 \% v$ $6 \%$ ) of non-compliant as compliant eyes showed deterioration (Table 3 ). It should be noted that non-compliance was not patient based, but rather caregiver based, and thus unlikely to be confounded by patients with undetected subtle organic disease.

There are two potential shortcomings of the data in the present study as well as that of some of the reanalysed studies. ${ }^{21}{ }^{22}$ One is that there is a possible selection bias in the fact that the subjects involved were of lower socioeconomic status than the general population who, conceivably, could have had a worse prognosis as a result of some characteristic of that status. In a study of this matter, however, no significant relation was found between a socioeconomic measure (Townsend deprivation score) and visual acuity outcome in children with anisometropic or mixed strabismic and anisometropic amblyopia. ${ }^{26}$ There was a marginally significant relation in strabismic patients, with such patients in the lower quartile on the socioeconomic measure exhibiting a marginally significant $(\mathrm{p}<0.04)$ and marginally poorer $(6 / 14.4 v 6 / 11.7)$ visual acuity outcome than those in the highest quartile. ${ }^{26}$ However, given the strong influence of compliance on amblyopia outcome, ${ }^{2122} 27-31$ and the fact that, as already noted, compliance has been found to be significantly correlated with socioeconomic status in studies where both are measured, ${ }^{2122}$ it seems likely that any apparent difference in outcome correlated with socioeconomic status is due to the reduced compliance, not inherently poorer prognosis.

A second possible shortcoming in the present study's data, and, although it is not made clear, almost certainly in that of the reanalysed studies, ${ }^{21}{ }^{22}$ is that the amblyopic eye's visual acuity was not measured through its best refractive correction, which would have been more ideal. However, in the present study at least, there were two controls present that make it unlikely that this shortcoming compromised the accuracy of the amblyopia diagnosis: (1) visual acuity was measured in both eyes, and the amblyopia defined as the difference between eyes, which controlled for visual acuity variability due to any bilateral change in the interval between the two screening measurements; and (2) cycloplegic refraction was performed at both screenings, with no refractive change found in 16 of the 18 patients. In the two patients who did exhibit change (Table 1 , cases 8 and 18), what change did occur would appear to be too marginal to be amblyopiogenic. It thus appears that the indicated amblyopia ascertainment was reliable, at least as regards its change, or lack of change, between the two screening examinations.

In summary, both the natural history data of the present study and those of the reanalysed earlier studies indicate that untreated children with either amblyopia or its risk factors are likely, at best, to show no improvement in the amblyopia if untreated and, in many cases, to exhibit deterioration or develop amblyopia initially if not treated.

A further reanalysis was also conducted of studies cited by the report ${ }^{12}$ in support of its contention of a benign natural history of untreated amblyopia. One of these studies compared outcome results in three groups of children screened by different healthcare personnel. ${ }^{11}$ Two of the groups were screened by non-eye care health personnel using only history and inspection for manifest strabismus, with one of these two groups also being administered a gross test of visual function. A third group was screened by eye care personnel, orthoptists, and was the only group tested for visual acuity, as well as other tests of ocular function. ${ }^{11}$ Substantially more cases of amblyopia associated with microtropia and anisometropia were detected and treated in this latter group than in the other two groups (43v 12 and 24, respectively, in Table $1^{11}$ ). However, the prevalence of amblyopia at the conclusion of the study was reported to be the same for all three groups, leading to the conclusion that some cases of amblyopia associated with microtropia or anisometropia in the two non-orthoptist screened groups resolved spontaneously, ${ }^{11}$ thereby apparently supporting the report's ${ }^{12}$ contention. Unmentioned in the report, however, but emphasised in the study itself, is the fact that the only outcome measure used, and the only acuity measure administered at any time to the non-orthoptist screened groups, was a "school eye test" ${ }^{11}$ No details are reported as to what this test comprised or who administered it, and the study itself notes that this test may have had poor sensitivity. ${ }^{11}$ In fact, there appears to be no adequately valid evidence of spontaneous regression of amblyopia in this study's data.

A second study cited by the report ${ }^{12}$ involved a group of 22 children referred following screening at 4 years of age, given no treatment, and followed up at 5 years of age. ${ }^{12}$ All at the first visit had visual acuity no worse than 0.65 in both eyes, or 0.8 in one eye and 0.65 in the other. At the retest at age 5, 18/22 had a visual acuity of 0.8 or better in both eyes. The report states that the four remaining children's vision that did not show an equivalent improvement in acuity also had not deteriorated $\left(\mathrm{p} \mathrm{19,}{ }^{1} \mathrm{p} 15^{2}\right)$. The results, reproduced in Table 5, appear to indicate otherwise. One case, case 2 , with a mild anisometropia (0.5 dioptre spherical equivalent) and equal vision 
at the first visit, maintained equal vision despite a slight apparent increase in anisometropia (to 0.625 dioptre spherical equivalent). However, cases 1 and 4, who had equal vision at age 4 , developed a difference in acuity between eyes at the follow up visit at age 5 and, for case 1 , at the final visit as well. Case 3 exhibited an increase in visual acuity difference between eyes between the visits at 4 and 5 years of age, with the laterality of the amblyopic and better eye reversing in the process. (The most likely explanation of the amblyopiogenic factor in at least cases 3 and 4 would appear to have been an undetected microtropia. The only test used in the study which could have detected microtropia was the TNO stereotest, which was passed by all children in the study at a 240 arc second level. ${ }^{12}$ However, some microtropes have been reported to be able to pass the TNO at this level, ${ }^{32-36}$ presumably on the basis of perifoveal stereopsis stimulated by its relatively large target size and coarse pixel structure ${ }^{17}$ and possibly due to interocular contrast asymmetry of its anaglyph format. ${ }^{36}$ ) Thus, for three of the four cases, the report's contention of non-deterioration ${ }^{12}$ appears contradicted.

Finally, a study is cited which reports a group of 20 adult patients with early onset esotropia who had never been treated, $15 \%$ of whom had developed amblyopia ${ }^{16}$ (and this amblyopia prevalence figure has been replicated in a similar, more recent study of 113 such patients ${ }^{24}$ ). The report concludes on the basis of this finding that "amblyopia was by no means an inevitable consequence of uncorrected cosmetically obvious squint" (p 20, ${ }^{1}$ p $16^{2}$ ). However, as already noted, amblyopia may have a lower prevalence in patients with large angle than small angle strabismus, since $80 \%(16 / 20)$ of the infantile esotropia patients in this study's sample whose angle of deviation was surgically reduced developed amblyopia for the first time post-surgically. ${ }^{16}$ Nine large sample population surveys summarised in one review found that amblyopia prevalence ranged from $42 \%$ to $186 \%$ of strabismus prevalence, with a median of $46 \%$ (Lennerstrand et al, Table $1^{37}$ ). If we assume that straight eyed anisometropia is responsible for $16-35 \%$ of amblyopia prevalence ${ }^{2138}$ or that anisometropia has $14-25 \%$ of the relative risk of strabismus in causing amblyopia, ${ }^{39}$ this means that amblyopia is a sequela of strabismus for $(100 \%-16 \%$ to $100 \%-35 \%)=84 \%$ to $65 \%$, or $(100 \%-14 \%$ to $100 \%-25 \%)=$ $86 \%$ to $75 \%$, times the $46 \%$ median, or $40 \%$ to $35 \%$ of cases of strabismus. In other words, if not "inevitable," this finding suggest that amblyopia will occur in somewhere between a third and a half of all strabismus cases.

(It might also be noted that, after citing evidence that hypermetropia which does not reduce with age during early development is a risk factor for strabismus, ${ }^{40-42}$ the report concludes that, none the less, early detection will "result in the correction of hypermetropia in many children in whom it would regress naturally." (p 20, ${ }^{1}$ p $16^{2}$.) Unmentioned is evidence that such correction may also prevent strabismus and/or amblyopia onset. ${ }^{43-46}$ )
A final set of data bearing on the natural history of amblyopia available in the extant literature is that concerning the upper age limit at which amblyopia can be induced, or the duration of the "sensitive period" for such onset. (There appear to be several different classes of sensitive period, ranging from vulnerability to loss of stereopsis to duration of the period during which visual acuity loss in the amblyopic eye can be effectively treated. ${ }^{47}{ }^{48}$ We will here use the term to refer to the upper age limit at which amblyopic visual acuity loss can be induced.) Most of this literature has been based on the visual response to ocular trauma or occlusion that gives rise to deprivation amblyopia. ${ }^{49-52}$ These risk factors may appear to constitute a more serious visual insult than strabismus and thus not pertinent to the strabismus risk factor in natural history. However, a study which compared (trauma induced non-comitant) strabismus and deprivation induced amblyopia found no significant difference in age of amblyopia onset of the two conditions. $^{52}$ This finding leads to the conclusion, then, that extant data show that sensitive period susceptibility to amblyopia extends to at least 6-7 years of age ${ }^{49-52}$-that is, that amblyopiogenic risk factors will in fact give rise to amblyopia until that time.

In conclusion, the present study provides no support for the idea that a prospective amblyopia treatment study could safely involve an untreated control group, ${ }^{129}$ but, on the contrary, demonstrates that failure to treat would put the control group at risk for deterioration of an existing amblyopia or initial development of amblyopia. Furthermore, the noncompliance based data presented and reviewed here, while not the product of formal randomised protocols, are the byproduct of prospective studies and do demonstrate the efficacy of amblyopia treatment, thereby reducing the need or justification for undertaking prospective studies in which treatment is deliberately withheld.

The authors thank David L Guyton, MD, David G Hunter, $\mathrm{MD}, \mathrm{PhD}$, and Susan Vitale, MHS, PhD, for comments on the manuscript.

This study was supported by grants from Mr Robert Feduniak This study was suppo
and Mr Robert Ball.

1 Snowdon SK, Stewart-Brown SL. Pre-school vision screening: results of a systematic review. York: NHS Centre for Reviews, 1997 (CRD Report 9).

2 Snowdon SK, Stewart-Brown SL. Pre-school vision screening. Health Technology Assessment 1997;1:1-98.

3 Rahi JS, Dezateux. The future of preschool vision screening Rahi JS, Dezateux. The future of preschool vision screen
services in Britain. (editorial). BMF 1997;315:1247-8.

4 Williams C, Harrad RA, Sparrow JM. Conclusions for or against services are invalid without appropriate research evidence (letter). BMf 1998;316:937.

5 Lee J, Adams G, Sloper J, et al. Cost effectiveness of screening for amblyopia is a public health issue (letter). BMF 1998;316:937.

6 Fielder AR. Review article did not separate review and implementation processes (letter). BMF 1998;316:937.

7 Aylward GW. The existence of a service is not evidence of its value (letter). BMF 1998;316:937.

8 Rahi J, Dezateux C. Authors' reply. BMf 1998;316:937.

9 Stewart-Brown SL, Snowdon SK. Evidence-based dilemmas in pre-school vision screening (editorial). Arch Dis Child 1998;78:406-7.

10 Moseley MJ. Preschool vision screening: a recent report calls for a halt (editorial). Br F Ophthalmol 1998;82:722-3.

11 Bray LC, Clarke MP, Jarvis SN, et al. Preschool vision Bray LC, Clarke MP, Jarvis SN, et al. Preschool vision
screening: a prospective, comparative evaluation. Eye 1996; 10:714-8.

12 Hård AL, Williams $P$, Sjöstrand $J$. Do we have optimal screening limits in Sweden for vision testing at the age of 4 years? Acta Ophthalmol Scand 1995;73:483-5. 
13 Aurrell E, Norrsell K. A longitudinal study of children with a family history of strabismus: factors determining the inci-

14 Ingram RM, Trynar MJ, Walker C, et al. Screening for refractive errors at age 1 year: a pilot study. $\mathrm{Br} \mathcal{F}$ Ophthalmol 1979;63:243-50

15 Ingram RM, Walker C. Refraction as a means of predicting squint or amblyopia in preschool siblings of children known to have these defects. Br f Ophthalmol 1979;63:23842.

16 Good WV, da Sa LFC, Lyons CJ, et al. Monocular visual outcome in untreated early onset esotropia. $\mathrm{Br} \mathcal{F}$ Ophthalmol 1993;77:492-4.

17 Simons K. Preschool vision screening: rationale, methodology and outcome. Surv Ophthalmol 1996;41:3-30.

18 Preslan MW, Novak A. Baltimore vision screening project. Ophthalmology 1996;103:105-9.

19 Preslan MW, Novak A. Baltimore vision screening project. Phase 2. Ophthalmology 1998;105:150-3.

20 Hiscox F, Strong N, Thompson JR, et al. Occlusion for amblyopia. A comprehensive survey of outcome. Eye 1992; 6:300-4.

21 Williamson TH, Andrews R, Dutton GN, et al. Assessment of an inner city visual screening programme for preschoo children. Br f Ophthalmol 1995;79:1068-73.

22 Hudak DT, Magoon EH. Poverty predicts amblyopia treatment failure. F AAPOS 1997;4:214-5.

23 Last JM, ed. A dictionary of epidemiology. 3rd ed. NewYork: Oxford University Press, 1995.

24 Calcutt C, Murray AND. Untreated essential infantile esotropia: factors affecting the development of amblyopia. Eye 1998;12:167-72.

25 Haase W, Wenzel F. The natural course of untreated functional amblyopia: does it progress between childhood and adulthood? Binoc Vis Strab Quart 1996;12:17-24.

26 Woodruff G, Hiscox F, Thompson JR, et al. Factors affecting the outcome of children treated for amblyopia. Eye 1994;8: 627-31.

27 Fulton AB, Mayer DL. Esotropic children with amblyopia: effects of patching on acuity. Graefes Arch Clin Exp Ophthalmol 1988;226:309-12.

28 Woodruff G, Hiscox F, Thompson JR, et al. Factors affecting the outcome of children treated for amblyopia. Eye 1994;8: 627-31.

29 Doran RML, Yarde S, Starbuck A. Comparison of treatment methods in strabismic amblyopia. In: Campos EC, ed. Strabismus and ocular motility disorders. London: Macmillan Press, 1990:51-9.

30 Levartovsky S, Oliver M, Gottesman N, et al. Factors affecting long term results of successfully treated amblyopia. $B$ f Ophthalmol 1995; 79:225-8.

31 Lithander J, Sjöstrand J. Anisometropic and strabismic amblyopia in the age group 2 years and above: a prospective study of the results of treatment. Br F Ophthalmol 1991;75: $111-16$.

32 Hill M, Perry J, Wood ICJ. Stereoacuity in microtropia. In Moore S, Mein J, Stockbridge S, eds. Orthoptics. Past, present, future. New York: Intercontinental, 1976.

33 Avilla CW, von Noorden GK. Limitation of the TNO random dot stereotest for visual screening. Am Orthopt $\mathcal{F}$ $1981 ; 31: 87-90$.
34 Rutstein RP, Eskridge JB. Stereopsis in small-angle strabismus. Am f Optom Physiol Opt 1984;61:491-8.

35 Hansell R. Stereopsis and ARC. Am Orthopt f 1991;41:1227.

36 Simons K, Elhatton K. Artifacts in fusion and stereopsis testing based on red/green dichoptic image separation. $\mathcal{F}$ Pediatr Ophthalmol Strabismus 1994:31:290-7.

37 Lennerstrand G, Jakobsson P, Kvarnström G. Screening or ocular dysfunction in children: approaching a common program. Acta Ophthalmol Scand 1995;Suppl 214:26-40.

38 Köhler L, Stigmar G. Vision screening of four-year-old children. Acta Pediatr Scand 1973;62:17-27.

39 Sjöstrand J, Abrahamsson M. Risk factors in amblyopia. Eye 1990;4:787-93.

40 Aurrell E, Norrsell K. A longitudinal study of children with a family history of strabismus: risk factors determining the incidence of strabismus. Br f Ophthalmol 1990;74:589-4.

41 Ingram RM, Traynar MJ, Walker C, et al. Screening for refractive errors at age 1 year: a pilot study. $\mathrm{Br} \mathcal{F}$ Ophthalmol 1979;63:243-50.

42 Ingram RM, Walker C. Refraction as a means of predicting squint or amblyopia in preschool siblings of children known to have these defects. Brf Ophthalmol 1979;63:23842 .

43 Ingram RM, Arnold PE, Dally S, et al. Results of a randomised trial of treating abnormal hypermetropia from the age of 6 months. Br $\mathcal{F}$ Ophthalmol 1990;74:158-9.

44 Atkinson J, Braddick O, Bobier B, et al. Two infant screening programmes: Prediction and prevents of strabismus and amblyopia from refractive screening. Eye 1996;10:18998 .

45 Ingram RM, Arnold PE, Dally S, et al. Emmetropisation, squint, and reduced visual acuity after treatment. $\mathrm{Br} f \mathrm{Oph}-$ thalmol 1991;75:414-6.

46 Friedburg D, Klöppel KP. Frühzeitige korrektion von hyperopie un astigmatismus bei kindern führ zu besserer entwicklung der sehschärfe. [Early spectacle correction of hypermetopia and astigmatism in childhood results in better development of visual acuity] Klin Monatsbl Augenheilkd 1996;209:21-4.

47 Von Noorden GK. Binocular vision and ocular motility. 5th ed. St Louis: Mosby, 1996:237.

48 Daw NW. Critical periods and amblyopia. Arch Ophthalmol 1998;116:502-5.

49 Assaf AA. The sensitive period: transfer of fixation after occlusion for strabismic amblyopia. Br F Ophthalmol 1982; 66:64-70.

50 Awaya S, Myake S. Form vision deprivation amblyopia: further observations. Graefes Arch Clin Exp Ophthalmol 1988;226:132-6.

51 Epelbaum M, Milleet C, Buisseret P, et al. The sensitive period for strabismic amblyopia in humans. Ophthalmology 1993;100:323-7.

52 Keech RV, Kutschke PJ. Upper age limit for the development of amblyopia. I Pediatr Ophthalmol Strabismus 1995;32:89-93. 